\title{
Assessment of Major Animal Health Problems and Their Impact on Beef Cattle Production in Doba District of West Harerghe Zone, Ethiopia
}

\author{
Umer Seid Geletu (D), ${ }^{1}$ Ahmedin Abdureman Musa, ${ }^{1}$ Sisay Lemma Waqe, \\ Munera Ahmednur Usmael, ${ }^{2}$ Yesihak Yusuf Mummed, ${ }^{3}$ Fufa Dawo Bari, \\ and Abdulmuen Mohammed Ibrahim ${ }^{5}$ \\ ${ }^{1}$ College of Agriculture, Department Animal Science, Oda Bultum University, P.O. Box 226, Chiro, Ethiopia \\ ${ }^{2}$ Oromia Bureau Livestock and Fishery Resources, West Hararghe Zone, Chiro Wereda, P.O. Box 226, Chiro, Ethiopia \\ ${ }^{3}$ School of Animal Science and Randge Land, Haramaya University, Dire Dawa, Ethiopia \\ ${ }^{4}$ Department of Microbiology, Immunology and Veterinary Public Health, College of Veterinary Medicine and Agriculture, \\ Addis Ababa University, P.O. Box 34, Bishoftu, Addis Ababa, Ethiopia \\ ${ }^{5}$ Office of Research Affairs, Haramaya University, Dire Dawa, Ethiopia
}

Correspondence should be addressed to Umer Seid Geletu; omerseid76@gmail.com

Received 7 February 2021; Accepted 5 August 2021; Published 24 August 2021

Academic Editor: Carlos Alberto Hussni

Copyright (c) 2021 Umer Seid Geletu et al. This is an open access article distributed under the Creative Commons Attribution License, which permits unrestricted use, distribution, and reproduction in any medium, provided the original work is properly cited.

\begin{abstract}
The aim of the current study was to assess the major animal health problems and their impact on beef cattle production in Doba district of West Harerghe Zone, Ethiopia. The study area was purposively selected, and a simple random sampling method was used to selected households' fatteners from each kebele and interviewed using structured questionnaires. The present study showed that the overall prevalence of the diseases was internal and external parasite $93.3 \%$, bloat $53.3 \%$, black leg $71.1 \%$, pasteurolosis $71.8 \%$, wound $71.8 \%$, FMD $22.2 \%$, and anthrax $13.33 \%$ which affect fattening cattle, respectively, in the study area. All the respondents (100\%) involved in the study were experienced with deworming of their animals to protect from parasites. But, only $46.7 \%$ and $42.2 \%$ of the respondents have accessed veterinary services with limited regularity and vaccination program, respectively, in the study area. Hence, the beef cattle fatting sector should be supported through considering alleviating the major disease affecting this sector and encouraging the farmers' indigenous knowledge practice with technology.
\end{abstract}

\section{Introduction}

The major constraints in fattening cattle production have been health problems because of the decrease of production, slow rate of regeneration, and amplification of the risk of disease transmission [1]. Infectious animal diseases that are endemic generate a variety of significant impact economically such as mortality, morbidity. Diseases have numerous negative impacts on productivity and fertility of herds [2]. Thus, knowing the status of major problems that constrain beef cattle fattening can help improving productivity and market success of producers; with the purpose of contributing in poverty reduction at all through marketoriented agricultural development [3].

Traditional backyard cattle fattening is widely practiced in highland areas. This type of cattle fattening was almost entirely dependent on locally available resources to minimize costs of fatting. In areas such as Hararghe, farmers buy young oxen from the nearer lowland area and use them for ploughing for a couple of years after which they fatten and sell them before they become old and emaciated [4].

The well-known benefits of conducting biosecurity for control and prevention of disease are improved efficiency of productivity $[5,6]$, keeping good welfare of the animals, 
boosting the response of immune systems to vaccines, and increased job satisfaction for producers [7]. Biosecurity practices were recommended by a number of studies based on different production systems. Almost all of the studies prefer the use of preventive procedures, but they do not often provide evidence on cost effectiveness [8].

Alhough Ethiopia is known for the largest cattle population, most beef was produced under an extensive production system, with low input system as a result of which beef production and productivity are very poor as compared to the world beef production. So far, there is no documented information regarding major animal health problems in Doba district of West Hararghe Zone of Eastern Ethiopia.

The general objective of the current study was

(i) To assess the major animal health problems and their impact on beef cattle production in Doba district of West Harerghe Zone, Eastern Ethiopia

The specific objective of the study was

(i) To identify major health problems of beef cattle in the study area and their associated risk factors

\section{Materials and Methods}

2.1. Descriptions of the Study Area. This study was conducted in selected kebeles of Doba district, West Harerghe Zone, Ethiopia (Figure 1). Doba district has 133,939 total populations of whom 68,512 were male and 65,427 were female and area coverage about $729 \mathrm{~km}^{2}$ or 72,900 hectares according to the census in 2007. It is one of the 17 districts in West Hararghe Zone, and it is located around $383 \mathrm{~km}$ east of Addis Ababa. Geographically, it is situated between $9^{\circ} 0^{\prime}$ to $9^{\circ}$ $30^{\prime}$ latitude and $40^{\circ} 57^{\prime}$ to $41^{\circ} 15^{\prime}$ longitude. Altitude ranges from 1,149 to 2,733 meters above sea level. The average temperature ranges from $21^{\circ} \mathrm{C}$ to $28^{\circ} \mathrm{C}$. The annual rainfall ranges from 650 to $750 \mathrm{~mm}$. The majority of the population is Muslim (86\%), and the primary language spoken is Afan Oromo [9].

\subsection{Sampling Size and Sampling Techniques}

2.2.1. Selection of the Study Area. Doba district was purposively selected based on nearer to main road and climatic condition. Accordingly, three kebeles from doba district, namely, Urji Berisa, Ifa Aman, and Gemechu were randomly selected. From each kebele, 15 cattle fatteners or owner was selected by the simple random sampling technique, and a total of 45 households were included in the current study and interviewed using structured questionnaires.

2.3. Data Collection and Analysis. A questionnaire was designed to get all information related to the major beef cattle fatting health problem in the study area. Agricultural experts, development agents, and veterinarians were key informant interviewees. Data were coded and entered into a Microsoft excel and analyzed using $R$ software. The analysis and summarization of the data was made using descriptive statistics.

\section{Results}

The overall respondents of cattle fattener showed that most of the interviewees $(86.7 \%)$ were male and the others were female (13.3\%) (see Table 1).

3.1. Occurrence of Diseases. The overall interviewed cattle fatteners $(100 \%)$ from the three kebeles reported the occurrence of animal health problems, especially parasites (internal and external) which affect beef cattle fattening (see Table 2). Out of the totally interviewed cattle fatteners, $41.66 \%$ of them have reported that they have experienced beef cattle loss due to death which directly affected their economy.

3.2. Control Measures against Diseases. All cattle fatteners $(100 \%)$ in the three kebeles have been practicing the deworming program to protect their beef cattle from internal and external parasites. However, only $53.33 \%$ and $41.66 \%$ of the respondents were accessed to veterinary services and vaccination practice in the study area (see Table 2).

Cattle fattening owners were also asked to describe major diseases, which affect beef cattle in the study area, and prioritize them based on their relative degree of importance. Respondents described diseases in their local names (see Table 3). These local names were given their veterinary equivalent name based on the symptoms mentioned and discussions with veterinarians in the area.

\section{Discussion}

According to the current study, the majority of respondents said that diseases are one of the most common limiting factors of the beef cattle fattening system in the area. In addition, they indicated that the disease was aggravated by a number of factors such as lack of veterinary service, lack of awareness of the society towards disease prevention and control program, and lack of attention to animal health from the government. Animal health professionals in the district have also explained that animal diseases are one of the main problems in the area, but there is a scarcity of drugs and vaccines for the treatment of their livestock due to lack of transport. Furthermore, the respondents reflected that they need to have the knowledge of how to improve their fattening cattle health condition by having access to drugs and some important vaccines.

The study showed that parasites were the most common health problems of cattle fatting in all three kebeles of the study area. Only $42.2 \%$ of cattle fatteners have vaccinated cattle against some of the diseases while entering the feedlot. This shows that a majority of the cattle fatteners in the study site do not know how to prevent disease in their farm before disease occurrence. Only $46.7 \%$ of the cattle fatteners involved in the study reported access to veterinary services from government organizations.

Black leg, bloat, pasteurelosis, and FMD (foot and mouth disease) are the most common infectious animal diseases of 


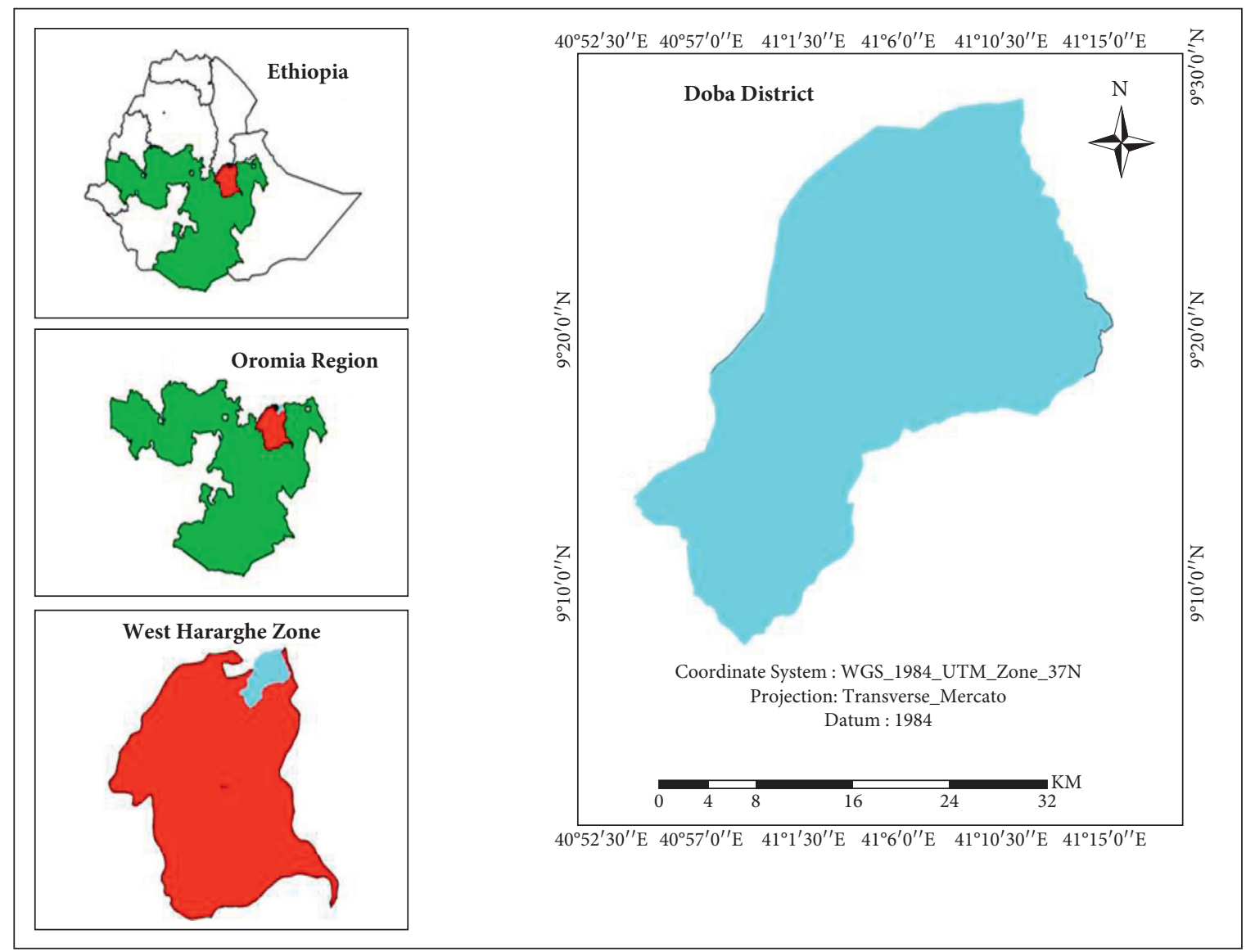

FIGURE 1: Map of the study area (source: the author).

TABLE 1: Demographic features of the respondents.

\begin{tabular}{|c|c|c|c|c|}
\hline Respondent's & $\mathrm{N}$ & Category & Frequency & $\%(\mathrm{n})$ \\
\hline \multirow{2}{*}{ Sex } & \multirow{2}{*}{45} & Male & 39 & 86.7 \\
\hline & & Female & 6 & 13.3 \\
\hline \multirow{3}{*}{ Educational status } & \multirow{3}{*}{45} & Illiterate & 30 & 66.7 \\
\hline & & Literate & 11 & 24.4 \\
\hline & & Primary school & 4 & 8.9 \\
\hline \multirow{2}{*}{ Family age size } & \multirow{2}{*}{45} & $<15$ years & 17 & 37.8 \\
\hline & & $\geq 15$ years & 28 & 62.2 \\
\hline
\end{tabular}

TABLE 2: Occurrence of diseases and producers' access to animal health protection facilities in the selected three kebeles of Doba district.

\begin{tabular}{|c|c|c|c|c|}
\hline Parameters & Ifa Aman \% (n) & Urji Berisa \% $(n)$ & Gemechu \% $(n)$ & Total \% (N) \\
\hline \multicolumn{5}{|c|}{ Occurrence of health problems } \\
\hline Yes & $100(15)$ & $100(15)$ & $100(15)$ & $100(45)$ \\
\hline No & $0.0(0)$ & $0.0(0)$ & $0.0(0)$ & $0.0(0)$ \\
\hline \multicolumn{5}{|c|}{ Vaccination practice } \\
\hline Yes & $33.3(5)$ & $40(6)$ & $53.3(8)$ & $42.2(19)$ \\
\hline No & $66.7(10)$ & $60(9)$ & $46.7(7)$ & $57.8(26)$ \\
\hline \multicolumn{5}{|c|}{ Deworming practice } \\
\hline Yes & $100(15)$ & $100(15)$ & $100(15)$ & $100(45)$ \\
\hline No & $0.0(0)$ & $0.0(0)$ & $0.0(0)$ & $0.0(0)$ \\
\hline \multicolumn{5}{|c|}{ Access to veterinary services } \\
\hline Yes & $46.7(7)$ & $40(6)$ & $53.3(8)$ & $46.7(21)$ \\
\hline No & $53.3(8)$ & $60(9)$ & $46.7(7)$ & $53.3(24)$ \\
\hline
\end{tabular}


TABle 2: Continued.

\begin{tabular}{lcccc}
\hline Parameters & Ifa Aman \% $(n)$ & Urji Berisa \% $(n)$ & Gemechu \% $(n)$ & Total \% $(\mathrm{N})$ \\
\hline Animal loss due to diseases & & & & \\
Yes & $53.3(8)$ & $33.3(5)$ & $26.7(4)$ & $37.8(17)$ \\
No & $46.7(7)$ & $66.7(10)$ & $73.3(11)$ & $62.2(28)$ \\
\hline
\end{tabular}

TABLE 3: Major diseases affecting beef cattle in the selected three kebeles of Doba district.

\begin{tabular}{|c|c|c|c|c|c|c|}
\hline Diseases & Local name & & Ifa Aman \% $(n)(n=15)$ & Urji\% $(n)(n=15)$ & Gemechu \% $(n=15)$ & Total \% (N), N=45 \\
\hline \multirow{2}{*}{ External parasites } & \multirow{2}{*}{ Raammoo } & Yes & $86.7(13)$ & $100(15)$ & $93.3(14)$ & $93.3(42)$ \\
\hline & & No & $13.3(2)$ & $0.0(0)$ & $6.7(1)$ & $6.7(3)$ \\
\hline \multirow{2}{*}{ Black leg } & \multirow{2}{*}{ Abbaa Gorbaa } & Yes & $80(12)$ & $73.3(11)$ & $60(9)$ & $71.1(32)$ \\
\hline & & No & $20(3)$ & $26.7(4)$ & $40(8)$ & 28.9 (13) \\
\hline \multirow{2}{*}{ Pasteurolosis } & \multirow{2}{*}{ Gorora } & Yes & $86.7(13)$ & $80(12)$ & $46.7(7)$ & $71.1(32)$ \\
\hline & & No & $13.3(2)$ & $20(3)$ & $53.3(8)$ & 28.9 (13) \\
\hline \multirow{2}{*}{ Bloat } & \multirow{2}{*}{ Bokoka } & Yes & $40(6)$ & $66.7(10)$ & $53.3(8)$ & $53.3(24)$ \\
\hline & & No & $60(9)$ & $33.3(5)$ & $46.7(7)$ & $46.7(21)$ \\
\hline \multirow{2}{*}{ Anthrax } & \multirow{2}{*}{ Abbaa sangaa } & Yes & $20(3)$ & $13(2)$ & $6(1)$ & $13.3(6)$ \\
\hline & & No & 80 (12) & $86.7 .3(13)$ & $93.3(14)$ & $86.7(39)$ \\
\hline \multirow{2}{*}{ Wound } & \multirow{2}{*}{ Madaa } & Yes & $20(3)$ & $33.3(5)$ & $13.3(2)$ & $22.2(10)$ \\
\hline & & No & 80 (12) & $66.7(10)$ & 86.7 (13) & $77.8(35)$ \\
\hline \multirow{2}{*}{ FMD } & \multirow{2}{*}{ Maasa } & Yes & $60(9)$ & $33.3(5)$ & $46.7(7)$ & $46.7(21)$ \\
\hline & & No & $40(6)$ & $66.7(10)$ & $53.3(8)$ & $53.3(24)$ \\
\hline
\end{tabular}

cattle fattening practice in Doba district (Table 3). Out of the total 45 respondents interviewed, $71.1 \%$ of them reported that it is the main disease challenging beef cattle production. This was in agreement with that described by Radiostits [10].

In the study area, the respondents reported that in $46.7 \%$, the FMD case affects their cattle fattening practice. FMD causes lower rates of live-weight gain in beef cattle production due to reduced feed intake [11]. The study revealed that anthrax is also the disease affecting beef cattle in the district because only $13.33 \%$ of the overall respondents reported the anthrax case in their cattle fattening practice.

The case of bloat in fattening beef cattle was common in the Doba district. Majority of the respondents (53.3\%) involved in the study reported that the bloating case is common.

\section{Conclusions and Recommendation}

The major constraint of beef cattle fattening production is the health problem due to decrease of production, slow rate of regeneration, and amplification of the risk of disease transmission. The overall interviewed cattle fatteners (100\%) from the three kebeles reported the occurrence of animal health problems, especially parasites which affects fattening cattle. The study indicated that the overall interviewed cattle fatteners reported the presence of diseases such as internal and external parasite, bloat, black leg, pasteurolosis, wound, FMD, and anthrax which affect fattening cattle by $(93.3 \%$, $53.3 \%, 71.1 \%, 71.8 \%, 71.8 \%, 22.2 \%$, and $37.8 \%$ ), respectively, in the study area. All the respondents (100\%) involved in the study have a practice of deworming to protect cattle from internal and external parasites. But, only $46.7 \%$ and $42.2 \%$ of respondents have accessed veterinary services with limited regularity and vaccination program, respectively, in the study area. Out of the totally interviewed cattle fatteners, $38.7 \%$ of them have reported that they have experienced animal beef cattle loss due to death which directly affected their economy.

Depending on the study, the following recommendations are forwarded:

(i) Beef cattle fatting owners should receive basic training regarding control and prevention animal diseases

(ii) Regular vaccination program against major animal diseases (blackleg, pasteurellosis, FMD, and anthrax) should be practiced

(iii) A proper animal health delivery system that could be extended to all livestock owner should be developed

\section{Data Availability}

The data used to support the findings of this study are available from the corresponding author upon request.

\section{Ethical Approval}

Ethical approval for this study was obtained from Oda Bultum University College of Agriculture Minutes of the Animal Research Ethics and Review Committee.

\section{Consent}

Verbal consent was also obtained from the farm managers to take samples from their cattle and for further research use of the samples.

\section{Conflicts of Interest}

The authors declare no conflicts of interest. 


\section{Authors' Contributions}

US contributed to conception of the research idea, designing and data collection, data analysis, interpretation of data, and writing and editing of the manuscript. MA contributed to the study concept, interpretation of data, and editing or reviewing of the manuscript. All authors read and approved the final manuscript. Umer Seid Geletu, Munera Ahmednur Usmael, Yesihak Yusuf Mummed, and Fufa Dawo Bari contributed equally.

\section{Acknowledgments}

The authors acknowledge Oda Bultum University for providing different facilities and reading materials used to prepare this manuscript and full funding.

\section{References}

[1] O. A. Adekunle, O. I. Oladele, and T. D. Olukaiyeja, "Indigenous control methods for pests and diseases of cattle in Northern Nigeria," Livestock Research for Rural Development, vol. 14, no. 2, 2002.

[2] Central Agriculture Census Commission, Ethiopian Agricultural Sample Enumeration, Land Use 2001-2002 (1994 E.C), pp. 29-43, Central Agriculture Census Commission, Addis Ababa, Ethiopia, 2017.

[3] K. Mekonnen, Major Animal Health Problems of Market Oriented Livestock Development in Alaba Woreda, Southern Nations Nationalities and People's region DVM Thesis, FVM, p. 21, Addis Ababa University, Debrezeit, Ethiopia, 2007.

[4] FAO, "Livestock, health, livelihoods and the environment in Ethiopia," in An Integrated Analysis, p. 108, FAO, Rome, Italy, 2019.

[5] G. Van Schaik, A. A. Dijkhuizen, G. Benedictus, H. W. Barkema, and J. L. Koole, "Exploratory study on the economic value of a closed farming system on Dutch dairy farms," Veterinary Record, vol. 142, no. 10, pp. 240-242, 1998.

[6] G. Van Schaik, M. Nielen, and A. A. Dijkhuizen, "An economic model for on-farm decision support of management to prevent infectious disease introduction into dairy farms," Preventive Veterinary Medicine, vol. 51, no. 3-4, pp. 289-305, 2001.

[7] A. W. Stott, J. Lloyd, R. W. Humphry, and G. J. Gunn, "A linear programming approach to estimate the economic impact of bovine viral diarrhoea (BVD) at the whole-farm level in Scotland," Preventive Veterinary Medicine, vol. 59, no. 1-2, pp. 51-66, 2003.

[8] M. L. Brennan and R. M. Christley, "Biosecurity on cattle farms: a study in north-west england," PLoS One, vol. 7, no. 1, Article ID e28139, 2012.

[9] CSA (Central Statistical Agency), Central Statistical Agency Population and Housing Census of Ethiopia, CSA, Addis Ababa, Ethiopia, 2007.

[10] O. M. Radostitis, Heard Health: Food Animal Production Medicine, pp. 1-45, WB Saunders Company, Philadelphia, PA, USA, 3rd edition, 2001.

[11] A. D. James and J. Rushton, "The economics of foot and mouth disease," Revue Scientifique et Technique de l'OIE, vol. 21, no. 3, pp. 637-644, 2002. 